\title{
Conceptualizing Sustainable Park (Uyana)
}

\author{
K. Jayantha ${ }^{1 *}$; RG.Ariyawansa ${ }^{2}$; U. Anura Kumara ${ }^{3}$ \\ ${ }^{1} \mathrm{PhD}$ candidate, University of Sri Jayewardenepura, Sri Lanka; Senior Lecturer, University of Kelaniya, Sri Lanka \\ ${ }^{2}$ Department of Estate Management and Valuation, University of Sri Jayewardenepura, Sri Lanka \\ ${ }^{3}$ Department of Business Economics, University of Sri Jayewardenepura, Sri Lanka \\ DOI: 10.29322/IJSRP.11.06.2021.p11404 \\ http://dx.doi.org/10.29322/IJSRP.11.06.2021.p11404
}

\begin{abstract}
Modern humans in the world suffer from the inability to fulfill their needs and wants. To overcome this suffering, scholars present a solution: sustainability. The human sufferers engage in recreational activities because they expect a temporary escape from misery. One such place for such activities is the park; even though the scholars' debate on the definitions of concepts such as park and sustainability. This debate motivated the authors of this paper to find a succinct method to conceptualize the sustainable park. The authors conduct eight studies prior to this paper from different points of views to provide a succinct conceptualization on the sustainable park. We used qualitative method and the grounded theory throughout the whole study based on the nature of our objectives. We fulfilled number of objectives within this study and previous studies such as proposing a definition for definition, creating a mechanism to measure the power of definition, and deriving the root definition of sustainability.
\end{abstract}

Index Terms- Definition, Park, Recreation, Sustainability

\section{INTRODUCTION}

$\mathrm{H}$ uman suffers until that person realizes the inability to fulfill his/ her own infinite desires. Leaving aside this simple truth, the academic community attempts to fulfill the needs and wants of the society. Academic community creates a number of concepts time to time with the aim of resolving human problems. Contemporary, fast running human often forgets tiny things. These fast-moving lifestyles resulted in losing humans' opportunity to think. Thus, surroundings made a man who knows the galaxy but unknown of him or herself. In such an environment, we started to learn about the sustainable park with an open mind. At the initial phase, nothing was known about both concepts: sustainability and park. It was excellent because the researchers had to initiate everything related to this process for the first time as nothing was known in the beginning. We started this process as a journey to find the best definition for the concept of sustainability. Meanwhile, we could find the most used definition of sustainability from the Brundtland Commission's report (Visser \& Brundtland, 2013). However, it was not the answer to our question, which was of what is the best definition for the concept of sustainability (Jayantha et al., 2020a, 2020b; Jayantha, Ariyawansa, \& Kumara, 2021b). After collecting dozens of definitions, we were confused. How can there be different definitions for one word? Leaving aside the main question we had to find the meaning of definition at first (Jayantha et al., 2020a). Accordingly, we started our first journey since then. We started to learn about definition of definition at first (Jayantha, Ariyawansa, \& Anura Kumara, 2021a). This new journey was a little bit difficult since linguistics and language studies were new to us. After an exhausting journey, we finally realized that many people still find it difficult to understand the meaning of a word (Jayantha et al., 2020a, 2020b; Jayantha, Ariyawansa, \& Kumara, 2021b). We understood that Russian and Indian scholars are at the forefront of this endeavor (Jayantha, Ariyawansa, \& Anura Kumara, 2021a). Even though those scholars have partially concluded, they have reached two plus points. The first is accepting that there is an eternal meaning of a word that can find through its sound (Jayantha et al., 2020a). And the second is that of the meaning of a word can derive using Nirukti (Jayantha et al., 2020a; Wisdom Library, 2018). However, because of combining the Nirukti studies with the Western ideology, scholars seemed to be misled and failed to get a hold of its real understandings. So, we started the study from their endpoint. Finally, we could finish our study starting from the two-plus points of existing literature which is not commonly used. Accordingly, the meaning of a word can be derived from itself by using Sakaya Nirukti and Gathi Guna, Gathi Handa, Gathi Ruwa which belongs to the word (Jayantha, Ariyawansa, \& Anura Kumara, 2021a). However, it should be understood that Sakaya Nirukthi (Levman, 2009; Rhys Davids \& Stede, 1925) is a kind of wisdom rather than some knowledge (Jayantha, Ariyawansa, \& Anura Kumara, 2021a; Jayantha, Ariyawansa, \& Kumara, 2021b). We finally came to the conclusion that obtaining a Nirukti of a word can led to understand the root meaning of a word (Jayantha, Ariyawansa, \& Anura Kumara, 2021a).

Then, we started another additional journey to measure the validity of existing definitions (Jayantha et al., 2020b). We used a very simple method to build up our argument. However, these findings were very important since they supported to measure the power of any kind of existing definition. We created a formula for measuring the power of definitions through this study (Jayantha et al., 2020b). According to the formula, it was hard to see a definition with power more than $12.5 \%$ (Jayantha et al., 2020b). Since inability to derive the root definition of a word, we found that most probably definitions seem to be practiced as descriptions or interpretations. At this point, we could say scientifically, that the power of existing definitions for sustainability is very weak. The power of such definitions is varied from $0.0014 \%$ to $12.5 \%$ (Jayantha et al., 2020b). This background with the knowledge of Nirukti, the next step which was to create a root definition for the concept of sustainability was taken. Having carefully using the Sakaya Nirukti method, we derived the root definition of 
sustainability. Accordingly, sustainability can be defined as 'letting Ariya Guna naturally open' (Jayantha et al., 2020a). There was another problem here. However, the definition was correct and was derived from the word. Yet definition's abstract form created a barricade to understand it. To correctly understand the definition of the words; concepts of 'nature' and 'Ariya Nature' had to be further clarified. Considering the necessity of clarifying the word 'nature' created another journey forward. Finally, we could understand nature as a combination of six parts (Jayantha, Ariyawansa, \& Kumara, 2021b). However, the word 'Ariya' was still to be clarified because of its uncommon nature. Since the word Ariya had wrong and different interpretations in the literature, it was a hard work for us to clarify the real meaning. After a deep and careful study, we finally understood of Ariya as the Right View (Jayantha, Ariyawansa, \& Anura Kumara, 2021c). These series of studies led us to create a root definition for the word sustainability now this journey has come to an end. At this point, sustainability can be defined as 'letting Right View naturally open' (Jayantha, Ariyawansa, \& Anura Kumara, 2021c). However, the two words 'Right View' have their own meanings rather than general understandings (Jayantha, Ariyawansa, \& Anura Kumara, 2021c).

The main objective of the study was conceptualizing sustainable parks. So far, our study defined only sustainability. Therefore, as the next step the word 'park' should be defined. This study reveals that the word 'park' is used in different meanings. For example, industrial parks and car parks are also included in this domain which is beyond recreation purposes. such practices maybe confusing the main idea of the park. Therefore, the word 'park' needs to have a perfect definition. Considering this necessity, we carefully studied this term. As it was difficult to find an ideal word in the English language for the term 'park' we suggested the word 'Uyana' instead of park. This term (Uyana) is common in Sri Lankan culture for more than 2500 years. This term: Uyana has a specific meaning as well. Thus, Uyana or park is a place where a specific type of population goes with a noble intention, which is to obtain mental and physical wellbeing (Jayantha, Ariyawansa, \& Kumara, 2021a).

\section{METHOD}

Basically, the study was launched in a questionable environment towards existing ideologies based on the grounded theory. Therefore, existing methodologies had to use carefully. Apart from that, we had to look for new methodologies such as Sakaya Nirukta, Prakrutha, Patichcha Samuppadaya, Four Noble Truth when required. The methods that we used throughout our entire journey are shown in Figure 1.

Figure 1: The methods of conceptualizing the sustainable park.

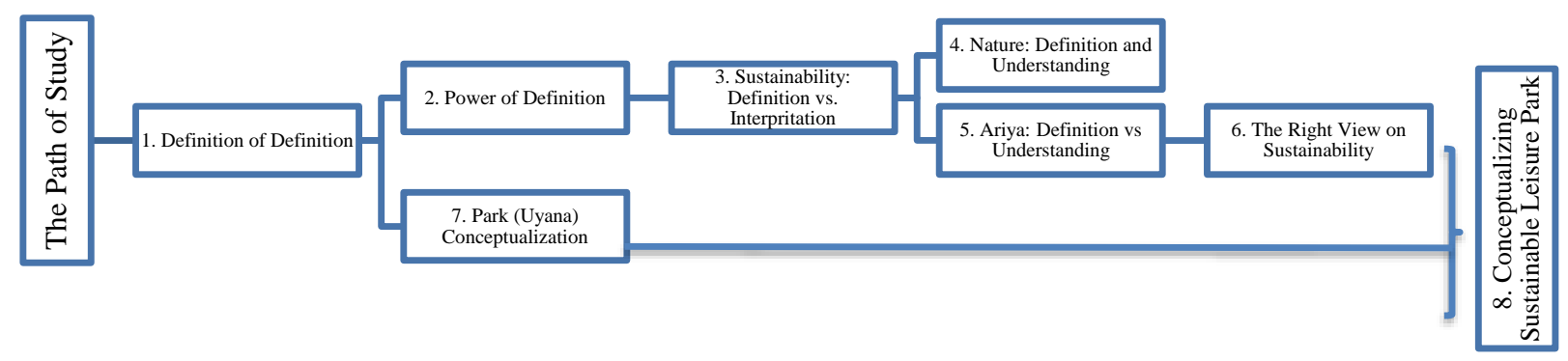

Source: Jayantha et al., 2020b; Jayantha, Ariyawansa, \& Anura Kumara, 2021c, 2021b; Jayantha, Ariyawansa, \& Kumara, 2021a, 2021b

The researchers belonged to the sport and recreation and management domains. Therefore, we were always careful not to administer wrong actions. We already knew by practice that the wrong steps would lead us to a failing end. Therefore, maintaining an open mindset caused a long investigation. We were questioning: Is the thing that we study align to nature? Looking at how the study phenomena was aligning with nature, was the method of this particular study series. The main part of this study was to assemble the knowledge of two concepts: sustainable (thirasaara) and park (uyana) as shown in Figure 2. 
Figure 2: The path of achieving the main objective: conceptualizing the sustainable park

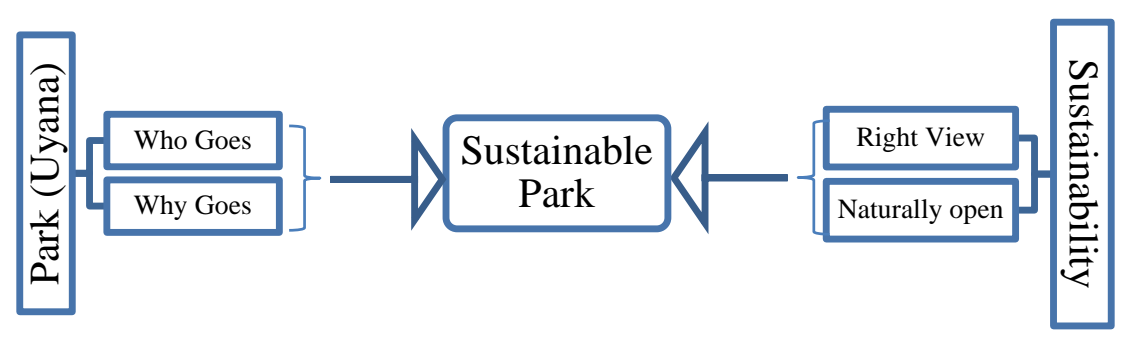

Source: Based on previously developed definitions (Jayantha, Ariyawansa, \& Anura Kumara, 2021c; Jayantha, Ariyawansa, \& Kumara, 2021a)

\section{Conceptualizing the Sustainable Park (Thirassara Uyana)}

Generally, park is defined as a place where people gather for the recreational activities (Hashim et al., 2019) The researcher argues that this definition should not mean all kinds of people as per the root definition (Jayantha, Ariyawansa, \& Anura Kumara, 2021a). According to the root definition, the people should be further specified as the noble ones, which we defined as Uthuman or Uththamayan. Then the definition of park should be further clarified as 'the place where noble people gather for recreational activities.' However, none still defined the word recreation in an accepted manner. Considering such barricades, the researcher defined the recreation as 'any of behavior that leads to the elimination of the existing uniformity'. Then finally park (Uayana) defined as the place where noble people gather for killing the existing uniformity (Jayantha, Ariyawansa, \& Kumara, 2021a).

Scholars and the public including policymakers use the concept of sustainability as a habit with their own definitions. Hundreds of definitions have been created so far during the last few decades. However, those definitions seem to be descriptions and interpretations rather than root definitions. In this attempt, we use the root definition of sustainability as 'letting the Right-View Naturally Open'(Jayantha et al., 2020a; Jayantha, Ariyawansa, \& Kumara, 2021b). Here there are two words that are needed to further clarifications: right view and naturally. To be something natural, there should be six factors: 1 a self-process. 2. right view 3. difficulty of imposing a timeframe 4. targeted the objectives 5 . raising up of the objectives and, 6. the science (Jayantha, Ariyawansa, \& Kumara, 2021b).

The next concept is the Right View. Some people say that 'right view' is a relative word. We suggest that the people say so about Right View, without a Right View. Right View is not a relative phenomenon. It is always based on science. It is based on the causes and effects relationship (Jayantha, Ariyawansa, \& Anura Kumara, 2021c). The causes-effects relationship should be read as a chain rather than to the individual incident. That is the way to understand the Right View. We have numbers of causeand-effect relationships that can be applied to reality. The concepts of Patichcha Samuppada Niroda, Chathurarya Sathya, the Noble Eightfold Path, Thilakshanaya and Majjhima Patipada are some of them. Especially we need the Right View for two reasons. The first is to recognize the root cause of a problem. The second is to understand the way of eliminating the cause. Using the patichcha samuppada causation theory we could realize the cause for scarcity as over-consumption. And further going through the chain, it was recognized the root cause of the over-consumption that is of 'the point initial attachment to extra wants'. As per the Right View, this is the cause that should be demolished. In other words, detaching the initial attachment towards extra wants can avoid over-consumption should be the right view of a person (Jayantha, Ariyawansa, \& Anura Kumara, 2021c).

\section{CONCLUSION}

We define park (Uyana) as the place where noble people visit to eliminate the existing uniformity. Detaching the initial attachment towards extra wants can avoid over-consumption. Overcoming over-consumption would answers the problem of the scarcity of resources. Such methods towards detaching the initial attachment should be fulfilling the six factors of nature: selfprocess, right view, difficulty of imposing a timeframe, targeted the objectives, raising up of the objectives and, the science. Accordingly, based on the abstract form: a park in which 'Letting the Right View Naturally Open' can be defined as a sustainable park. Elaborated version of the same definition or a sustainable park would be: A place that 'Detach the initial-attachment towards the extra wants, while fulfilling the six nature factors.

\section{REFERENCES}

[1] Hashim, N. I., NHS, Y., Aris Anuar, A. N., \& Sulaiman, F. C. (2019). The Restorative Environment Offered by Pocket Park at Laman Standard Chartered Kuala Lumpur. Journal of Hotel and Business Management, 08(01). https://doi.org/10.35248/2169-0286.19.8.194

[2] Jayantha, K., Ariyawansa, R., \& Anura Kumara, U. (2020a). Sustainability: Definitions Vs Interpretations. International Journal of Scientific and $\begin{array}{lll}\text { Research } & \text { Publications, } & \text { 10(9), }\end{array}$ https://doi.org/10.29322/IJSRP.10.09.2020.p10539

[3] Jayantha, K., Ariyawansa, R., \& Anura Kumara, U. (2021a). Definition of Definition. International Journal of Multidisciplinary Studies (IJMS), University of Sri Jayewardenepura. http://graduate.sjp.ac.lk/internationaljournal-of-multidisciplinary- studies

[4] Jayantha, K., Ariyawansa, R. G., \& Anura Kumara, U. (2020b). Which Definition Should We Select? Power of Definitions. European Journal of Social Sciences, 60(4), 285-301. http://www.europeanjournalofsocialsciences.com/

[5] Jayantha, K., Ariyawansa, R. G., \& Anura Kumara, U. (2021b). Ariya: Definitions andUnderstanding. Journal of Social Sciences, Faculty of Social Sciences,University of Kelaniya, In Press. 
[6] Jayantha, K., Ariyawansa, R. G., \& Anura Kumara, U. (2021c). Right view on Sustainability. KALYĀNI, 2. Journal of the University of Kelaniya, Research and PublicationDivision, University of Kelaniya, Sri Lanka

[7] Jayantha, K., Ariyawansa, R. G., \& Kumara, U. A. (2021a). Park (Uyana). Scholars Journal of Arts, Humanities and Social Sciences, 9(5), 144-157. https://doi.org/10.36347/sjahss.2021.v09i05.002

[8] Jayantha, K., Ariyawansa, R. G., \& Kumara, U. A. (2021b). SWA+BHAAWA (NATURE): DEFINITION AND UNDERSTANDING. European Journal of Social Sciences Studies, 6(2). https://doi.org/10.46827/ejsss.v6i2.1011

[9] Levman, B. (2009). Sakaya niruttiya revisited (pp. 33-51). http://www.sareligionuoft.ca/wp-content/uploads/2013/01/Levman-sakāyaniruttiyā.pdf

[10] Rhys Davids, T. W., \& Stede, W. (1925). Pali Text Society's Pali-English Dictionary (T. W. Rhys Davids \& W. Stede (eds.)). http://www.archive.org/details/palitextsocietys00pali/

[11] Visser, W., \& Brundtland, G. H. (2013). Our Common Future ('The Brundtland Report'): World Commission on Environment and Development. The Top 50 Sustainability Books, 52-55. https://doi.org/10.9774/gleaf.9781-907643-44-6_12
[12] Wisdom Library. (2018, June 22). Ranmasu Uyana: 1 definition. Info@wisdomlib.Org . https://www.wisdomlib.org/definition/ranmasuuyana\#history

\section{AUTHORS}

First Author - K. Jayantha, PhD candidate, University of Sri Jayewardenepura, Sri Lanka; Senior Lecturer, University of Kelaniya, Sri Lanka; kala@kln.ac.lk

Second Author - RG.Ariyawansa, Department of Estate Management and Valuation, University of Sri Jayewardenepura, Sri Lanka; ariyaw71@sjp.ac.lk

Third Author - U. Anura Kumara, Department of Business Economics, University of Sri Jayewardenepura, Sri Lanka; uthumange@sjp.ac.lk 